\title{
AN ObJeCt-ORIENTEd GRapHICAL APPROACH FOR TEACHING ELECTRIC MACHINERY ANALYSIS
}

\author{
Stephen M. Williams Daniel B. Kline \\ Member \\ Student Member \\ Naval Postgraduate School \\ Monterey, CA
}

\begin{abstract}
This paper presents a teaching method used at the Naval Postgraduate School for electric machinery analysis. An objected-oriented, graphical tool for real-time simulation of electric machines is described. An undergraduate exercise is detailed to show how the use of the new analysis techniques significantly enhances the learning process. Rapid modeling of electric machines and subsequent simulation results encourage the student to explore machine behavior under a variety of transient and steady state operating conditions, thus significantly broadening the students knowledge of electric machinery.
\end{abstract}

\section{INTRODUCTION}

With the increasing application of power electronics to electric machinery, there is a need for a sequence of electric machinery analysis undergraduate and graduate courses. The analysis of systems with electromechanical energy conversion coupled to static power converters requires a thorough knowledge of reference frame theory [1] and application of computer-aided engineering techniques. Such analysis must be presented at the undergraduate level. Design and synthesis of such systems can then be introduced to undergraduates and further refined at the graduate level.

Historically, electric machine analysis results were obtained from analog and hybrid analog/digital computers due to the nonlinear nature of the equations modeling the systems [2]. More recently, computer

93 SM 554-6 PWRS A paper recommended and approved by the IEEE Power Engineering Education Committee of the IEEE Power Engineering Society for presentation at the IEEE/PES 1993 Summer Meeting, Vancouver, B.C., Canada, July 18-22, 1993. Manuscript submitted

Jan. 4, 1993; made avallable for printing June 7 , 1993.

PRINTED IN USA simulations have been performed on costly mainframe computers with extensive programming efforts. The advent of object-oriented, graphical simulation programs and high powered, inexpensive microcomputers has made computer based analysis of electric machinery available at all major universities.

The analysis of electric machines invariably involves the study of machine performance during free acceleration, changes in load torque, fault conditions, and changes in the source voltage waveform. Machinery analysis textbooks usually present a few examples with corresponding graphs [3-5]. For students to be able to set up their own simulations and then to observe real-time plots of system variables during the simulation greatly improves student interest, comprehension and retention. The recent advances in object-oriented graphical simulation software permits such real-time studies.

This paper is based on two extremely effective machine analysis courses being taught at the Naval Postgraduate School. The courses utilize the graphical simulation package developed by Mathworks SIMULINK [6]. The nonlinear machine equations are readily developed into working machine models allowing students to vary system parameters and to change operating conditions; thus enriching their understanding of electric machine analysis.

\section{Motivation}

The electric machinery sequence at the Naval Postgraduate School is the first exposure most students have to reference frame theory. A prerequisite to the sequence is an introductory course in electric machines. Non-saturating magnetic circuits are used in class to develop machine models. Students are then provided with software models of the machines being studied. Assignments are to analyze machine behavior under the following conditions: free acceleration from startup, step changes of various type loads, source imbalance, and bolted faults. Students are able to change model parameters and operating conditions in order to observe the machines performance. 
In the graduate electric machinery analysis course, students develop their own electric machine models, incorporate the saturation effects of the magnetic circuits, and also integrate machines into power systems to observe power system performance and stability. such as:

In the classroom, the ability to field questions

'...what if the fault had not cleared for another and 0.2 seconds ?...'

$\therefore$...how would the rotor voltages appear as viewed in a different reference frame?...',

can easily be addressed, discussed, and then observed during a machines simulated operation utilizing the graphical models of the various machines.

Being able to immediately observe conditional scenarios has increased student interest and understanding of machine dynamics. When first introduced to the reference frame theory approach to machine analysis, most students have difficulty grasping the abstract concepts. To visually demonstrate the application of various reference frames and their advantages/disadvantages during classroom discussion significantly contributes to the students comprehension.

\section{MAChine Modeling}

Successful models have been constructed of a dc machine, an induction machine, and a synchronous machine. All three machine models involve nonlinear differential equations which are easily handled with nonlinear blocks included in the graphical simulation package. For brevity, only the induction machine model will be developed in this paper.

The induction machine equations in the arbitrary reference frame can be expressed in (1) where $p$ is the differential operator. For illustrative purposes, the equation for $v_{q s}$ is expanded and solved in terms of flux-linkages per second:

$$
v_{q s}=r_{s} i_{q s}+\frac{\omega}{\omega_{b}} \psi_{d s}+\frac{p}{\omega_{b}} \psi_{q s}
$$

where

$$
\begin{aligned}
& \Psi_{q s}=X_{l s} i_{q s}+X_{m}\left(i_{q s}+i_{q r}^{\prime}\right) \\
& \Psi_{d s}=X_{l s} i_{d s}+X_{m}\left(i_{d s}+i_{d r}^{\prime}\right) \\
& X_{s s}=X_{l s}+X_{m}
\end{aligned}
$$

The current can be found

Using

$$
i_{q s}=\frac{1}{X_{l s}}\left(\Psi_{q s}-\Psi_{m q}\right)
$$

$$
\Psi_{m q}=X_{m}\left(i_{q s}+i_{q r}^{\prime}\right)
$$

gives the voltage equation

$$
v_{q s}=r_{s}\left[\frac{1}{X_{l s}}\left(\Psi_{q s}-\Psi_{m q}\right)\right]+\frac{\omega}{\omega_{b}} \psi_{d s}+\frac{p}{\omega_{b}} \Psi_{q s}
$$

and solving for flux-linkages per second in order to put the equation in integral form

$$
\psi_{q s}=\frac{\omega_{b}}{p}\left[v_{q s}-\frac{\omega}{\omega_{b}} \psi_{d s}+\frac{r_{s}}{X_{L s}}\left(\psi_{m q}-\Psi_{q s}\right)\right]
$$

This format is repeated for the remaining equations in (1). From voltage equation (7), the SIMULINK implementation is shown in Fig. 1.

$$
\left[\begin{array}{c}
v_{q s} \\
v_{d s} \\
v_{0 s} \\
v_{q r}^{\prime} \\
v_{d r}^{\prime} \\
v_{0 r}^{\prime}
\end{array}\right]=\left[\begin{array}{cccccc}
r_{s}+\frac{p}{\omega_{b}} X_{s s} & \frac{\omega}{\omega_{b}} X_{s s} & 0 & \frac{p}{\omega_{b}} X_{M} & \frac{\omega}{\omega_{b}} X_{M} & 0 \\
-\frac{\omega}{\omega_{b}} X_{s s} & r_{s}+\frac{p}{\omega_{b}} X_{s s} & 0 & -\frac{\omega}{\omega_{b}} X_{M} & \frac{p}{\omega_{b}} X_{M} & 0 \\
0 & 0 & r_{s}+\frac{p}{\omega_{b}} X_{l s} & 0 & 0 & 0 \\
\frac{p}{\omega_{b}} X_{M} & \left(\frac{\omega-\omega_{r}}{\omega_{b}}\right) X_{M} & 0 & r_{r}^{\prime}+\frac{p}{\omega_{b}} X_{r r}^{\prime} & \left(\frac{\omega-\omega_{r}}{\omega_{b}}\right) X_{r r}^{\prime} & 0 \\
-\left(\frac{\omega-\omega_{r}}{\omega_{b}}\right) X_{M} & \frac{p}{\omega_{b}} X_{M} & 0 & -\left(\frac{\omega-\omega_{r}}{\omega_{b}}\right) X_{r r}^{\prime} & r_{r}^{\prime}+\frac{p}{\omega_{b}} X_{r r}^{\prime} & 0 \\
0 & 0 & 0 & 0 & r_{r}^{\prime}+\frac{p}{\omega_{b}} X_{l r}^{\prime}
\end{array}\right]\left[\begin{array}{l}
i_{q s} \\
i_{d s} \\
i_{0 s} \\
i_{q r}^{\prime} \\
i_{d r}^{\prime} \\
i_{0 r}^{\prime}
\end{array}\right](1)
$$




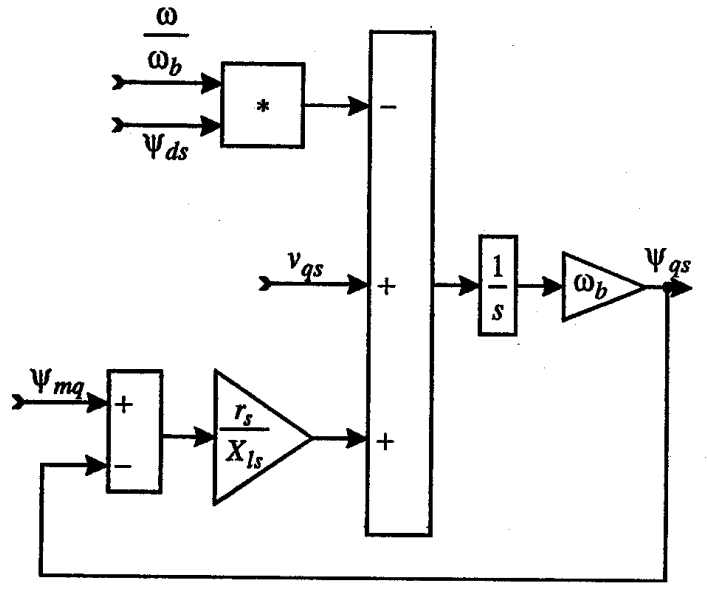

Fig. 1. Actual computer implementation of (7).

From the entire set of voltage equations (1), the induction machine model is shown in Fig. 2. As can be seen, the inputs are the stator voltages, load torque, and reference speed (motor operation assumed) and the outputs are the electrical torque, the currents, and the rotor speed.

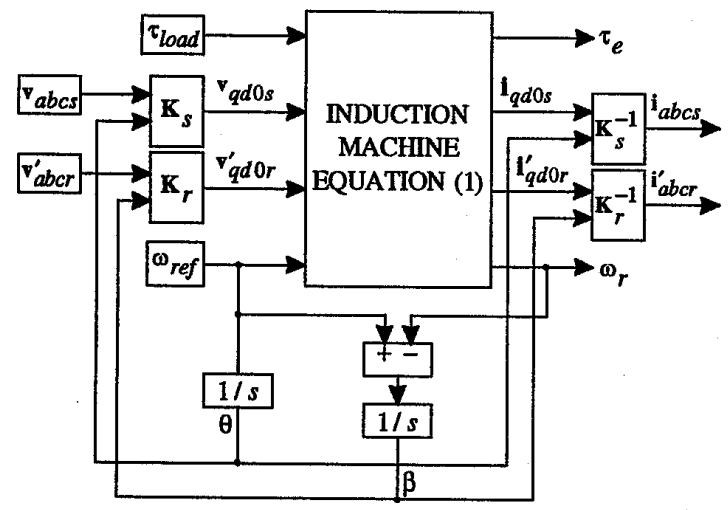

Fig. 2. Induction machine model.

\section{Classroom APPlication}

As stated previously, students in the undergraduate course are provided with the model shown in Fig. 2. One assignment is to determine machine performance during free acceleration and during a change in load torque. Simulation results are shown in Figs. 3 to 6 for a 3 phase, $10 \mathrm{HP}, 220 \mathrm{~V}$, $60 \mathrm{~Hz}$ induction motor.
Rotor Current (Stationary Reference)

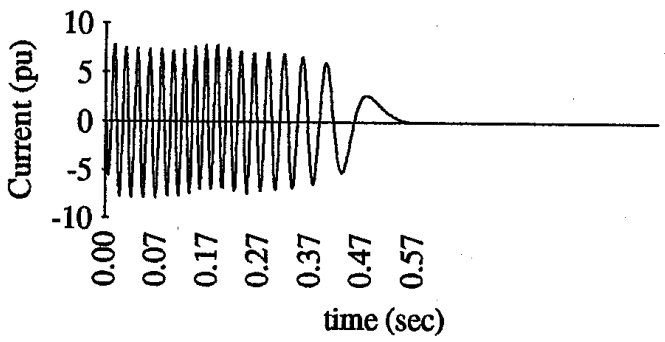

Fig. 3. Free acceleration of induction machine.

Torque vs. Speed

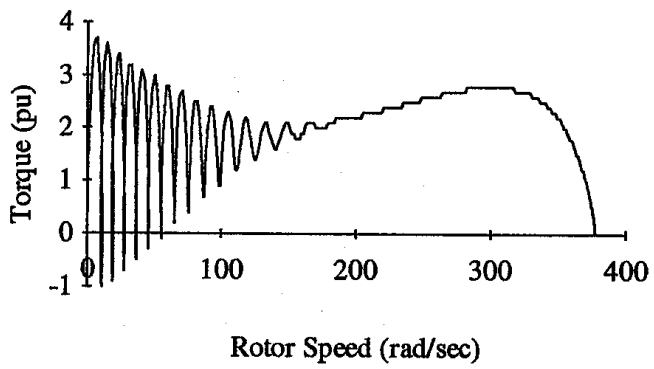

Fig. 4. Free acceleration of induction machine.

Rotor Current (Stationary Reference)

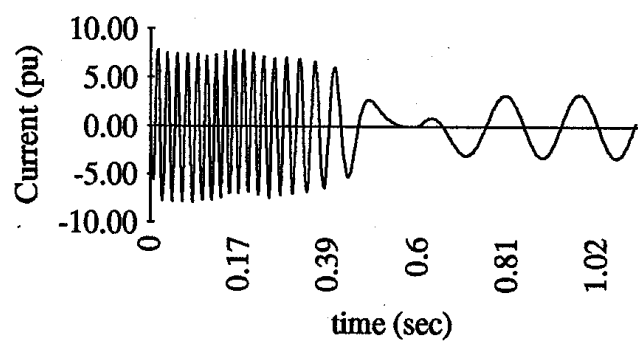

Fig. 5. Zero to 2.5 pu change in load torque of induction machine.

Torque vs. Speed

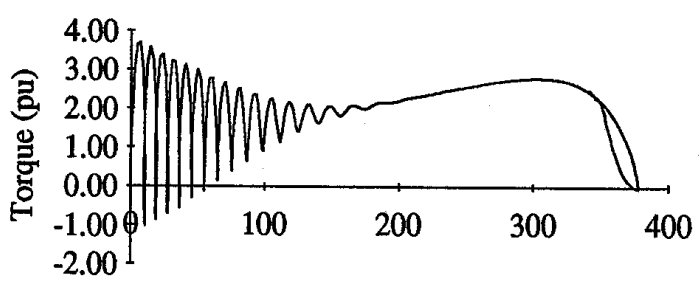

Rotor Speed ( $\mathrm{rad} / \mathrm{sec})$

Fig. 6. Zero to 2.5 pu change in load torque of induction machine. 


\section{Conclusion}

Machine modeling in an object-oriented graphical environment on a personal computer greatly improves the students ability to grasp difficult concepts related to the analysis of electric machinery. By utilizing these techniques both during classroom lectures and in student laboratories, the student can experiment with machine performance analysis beyond what is covered in the textbook. This motivates the student to experiment with various machine simulations without the need to write extensive computer code, to compile programs, or to convert the raw data to useful plots. With currently available graphical based software, the student can change system parameters and observe the effects on variables of interest while the simulation takes place.

Severe time constraints due to the large amount of information to be taught cause many questions in the classroom to receive insufficient attention. With the current software packages available however, this is no longer the case. Questions now lead to meaningful, quantitative discussions coupled with real-time graphical simulations. Students now complete these classes with a more in-depth comprehension than in the past without the analysis software.

\section{REFERENCES}

[1] P.C. Krause, "Method of Multiple Reference Frames Applied to the Analysis of Symmetrical Induction Machinery," IEEE Transactions on Power Apparatus and Systems, Vol. 87, no. 1, January 1968, pp. 218-227.

[2] P.C. Krause, C.H. Thomas, "Simulation of Symmetrical Induction Machinery," IEEE
Transactions on Power Apparatus and Systems, Vol. 84, no. 11, November 1965, pp. 1038-1053.

[3] P.C. Krause, Analysis of Electric Machinery, McGraw-Hill Book Company, New York, 1986, pp. 189-208.

[4] G.R. Slemon, Electric Machines and Drives, Addison-Wesley, New York, 1992, pp. 394-409.

[5] A. Greenwood, Electrical Transients in Power Systems, John Wiley \& Sons, New York, 1991, pp. 355-363.

[6] The Mathworks, Inc., Simulink Reference Manual, 1992.

Stephen M. Williams (S'81-M'85) has been an Assistant Professor in the Department of Electrical and Computer Engineering at the Naval Postgraduate School since September 1990. Prior to joining NPS he was a research assistant at the Power Electronics Research Center. He also has held a position as an automated test equipment engineer designing microprocessor based test sets at Allied Signal Corporation under contract with the Department of the Navy in conjunction with the Department of Energy.

Daniel B. Kline (S'91) was born May 3, 1959 in Minneapolis, Minnesota. He received a B.S. degree in Electrical Engineering from Oregon State University in 1987. He has served in the United States Navy since 1977 and is presently a Lieutenant in the submarine service pursuing the Master's degree in Electrical Engineering specializing in power systems at the Naval Postgraduate School. 